\title{
Three-Phase Reference Current Generator Employing with Kalman Filter for Shunt Active Power Filter
}

\author{
Ahmad Shukri Abu Hasim ${ }^{\dagger}$, Zulkifilie Ibrahim*, Md. Hairul Nizam Talib* and \\ Syed Mohd. Fairuz Syed Mohd. Dardin**
}

\begin{abstract}
This paper presents a new technique of reference current generator based on Kalman filter (KF) estimator for three-phase shunt active power filter (APF). The stationary reference frame $(d-q$ algorithm) is used to transform the load currents into DC component. The harmonics of load currents are extracted and the three-phase reference currents are generated using KF estimator. The work is simulated using Matlab/Simulink platform. To validate the simulation results, an experimental test-rig have been perform using real-time control dSPACE DS1104. In addition, hysteresis current control was used to generate the switching signal for the correction of the harmonics in the system. The nonlinear load were constructed with three-phase rectifier which connected in series with inductor and parallel with resistor and capacitor. The results shows that the new technique of shunt APF embedded with $\mathrm{KF}$ is proven to eliminate the harmonics created by the non-linear load with some improvement on the total harmonics distortion (THD).
\end{abstract}

Keywords: Active power filter, Harmonics, Kalman filter estimator, Non-linear load

\section{Introduction}

Harmonics interference in power system become increasingly critical due to the wide application of power electronic equipment of non-linear load and harmonics contamination that affects the power quality of the system. Various methods have been proposed to solve these problems. One of the method is by using passive filter which connected in parallel with non-linear loads (NLL) resulting in the improvements of the power factor [1], harmonic suppression [2] and exhibit lower impedance at a tuned harmonics frequency [3]. This approach is popular due to its simplicity, reliability, efficiency and low cost [4], but at the expense of providing incomplete solutions particularly when compensating random frequency variations in the current, tuning and parallel resonant problems. In recent years, various active power filters (APF) configuration with their respective control strategies have been proposed and have been recognized as a viable solution to the problem created by harmonics [5-7]. Amongst the technique that have been developed are the extraction and the estimation approach. Instantaneous reactive power theory ( $p-q$ theory), modified $p-q$ theory [8-10], $p-q-r$ theory $[11,12]$, vectorial theory [13] and $d-q$ theory $[7,14,15]$ are the techniques that fall into the

$\dagger$ Corresponding Author: Dept. of Electrical and Electronic Engineering, Universiti Pertahanan Nasional Malaysia, Malaysia. (shukri@upnm.edu.my)

* Faculty of Electrical Engineering, Universiti Teknikal Malaysia Melaka, Malaysia. (\{drzulkifiliee, hairulnizam\}@utem.edu.my)

** Dept. of Electrical and Electronic Engineering, Universiti Pertahanan Nasional Malaysia, Malaysia. (syedfairuz@upnm.edu.my)

Received: February 25, 2016; Accepted: July 18, 2016 extraction technique. In many cases, $d-q$ algorithm have been widely used to eliminated the harmonics due to its simplicity of control design relative to the rest [6].

On the other hand, estimation approach is used to estimate harmonics of frequency component present in the signal and measurement or estimation of the amplitude and phases of those frequencies [16]. These approach can be divided into two classes, non-parametric and parametric methods. The non-parametric methods are based on transformation of the given time-series data sequence. During the estimation process, this methods are not capable of incorporating with any available information about the system. Frequency domain approach using Fourier transform is the most commonly used for spectrum analysis in this harmonics estimation [16]. In addition, parametric methods use an appropriate model to represent the signal and then estimate the parameters of the model from the available data points. Estimated parameter are applied to the selected model to determine harmonics contents in the signal. This parametric methods offer higher resolution and better accuracy compared to the non-parametric methods [16]. KF estimator is one of the methods that fall into the parametric method category which have been widely studied and used for different applications [16-23]. In active power filter, KF is used to estimate and track the current harmonics of the grid which reported in [24-26]. In this technique, it is assume that the frequency of the grid are constant and its only detect the harmonics in the system. Furthermore, the DC NLL have been used by many researchers to generate the distorted current waveform [5, 27-31]. Generally, the NLL is constructed using combination of resistor, inductor and 
capacitor (RLC). The inductor is connected in series with parallel resistor and capacitor. This non-linear loads created various problems to the system which can eliminated using shunt APF.

Generally, the $d-q$ algorithm using Butterworth low-pass filter used to filter out the unwanted DC component to ensure the correct reference currents are been generated in the system. Fail to obtain the corrected reference current will reduce the overall performance of the active power filter (APF). However, time delay introduce when applying the low-pass filter will contribute to the phase shift in harmonics and high transient current [32-34]. Therefore, this paper proposed a new technique of the current reference generator embedded with KF estimator for shunt APF system. This technique reduce the time delay thus produced improvement of the overall total harmonics distortion (THD) in the system.

\section{Shunt Active Power Filter}

The typical connection of the three-phase shunt active power filter (APF) is shown in Fig. 1.

The inverter act as voltage source which capable of blocking harmonics current that flow from the non-linear load. The APF system is the feedback system that monitor the supply current, $I_{S a} I_{S b}$, and $I_{S c}$. The corrective signals for generating compensation current, $I_{i n j(a b c)}$ are required for injection into the supply system which are done at the harmonics detection using $d-q$ algorithm. In this reference current generation, harmonics from the loads current are extracted/estimated to generate the reference signal which are then subtracted with the non-linear load current to produce the corrected signal. Then, the corrective PWM are generated and injected to the system through the voltage source inverter. The magnitude of the compensated current must be in a correct amplitude with respect to the load. The magnitude of the compensated current must match with the power drawn from the supply and capable

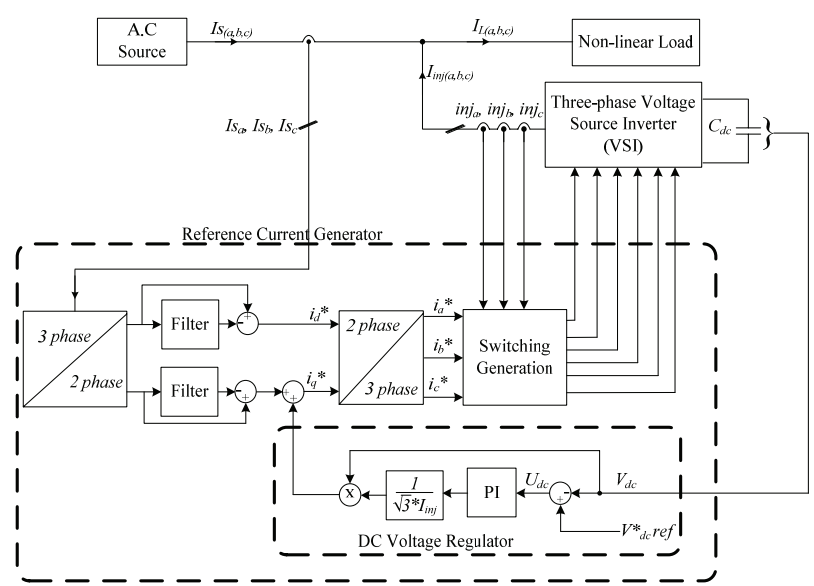

Fig. 1. Shunt active power filter configuration
Table 1. System parameters

\begin{tabular}{c|c|c}
\hline Parameter & Notation & Values \\
\hline Source Voltage & $V_{S}$ & $120 \mathrm{Vrms}$ \\
\hline Source frequency & $f$ & $50 \mathrm{~Hz}$ \\
\hline DC link capacitor & $C_{d c}$ & $2200 \mu \mathrm{F}$ \\
\hline Line Inductor & $L_{i n}$ & $3 \mathrm{mH}$ \\
\hline Load Capacitor & $C_{L}$ & $2200 \mu \mathrm{F}$ \\
\hline Load Resistance & $R_{L}$ & $100 \Omega$ \\
\hline
\end{tabular}

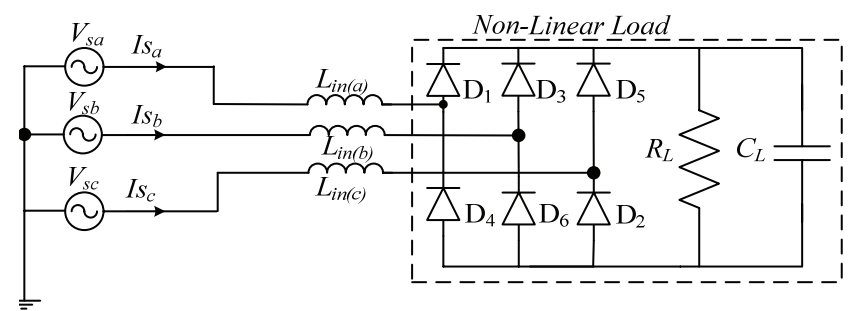

Fig. 2. Non-Linear Load

in matching the load power together with the losses in the compensator. Therefore, DC voltage regulator is used to provide the magnitude of the desired current which correspond to the amplitude of the fundamental component of the load plus the losses. The simulation and experimental studies on KF estimator for three-phase reference current generation are carried out using the system parameters as mentioned in Table 1.

\subsection{Non-linear load}

The non-linear load consists of three-phase bridge rectifier connected to the voltage supply by means of linear inductor $\left(L_{i n}\right)$ feeding resistor and capacitor load as shown in Fig. 2. The pulsating current waveform being drawn from supply line current are obtain in this circuit.

\subsection{Kalman filter based reference current generator}

In this new technique, the KF use a form of feedback control in which the filter estimates the process at any time and then obtains feedback in the form of noisy measurement. As such, equations of the KF is implemented in two steps; time update and measurement update equations. The time update also known as predicator equation is responsible for projecting forward (in time) the current state and error covariance estimate to obtain the estimation in the next time step. While the measurement update equation also called corrector equations are responsible for the feedback such as for incorporating a new measurement into the estimator to further improve the estimation. Therefore the estimation resembles the combination of predicator-corrector algorithm which used in the system. Originally KF was designed for linear systems based which define as;

$$
\begin{gathered}
x_{k}=A x_{k-1}+B u_{k-1}+w_{k-1} \\
z_{k}=H x_{k}+v_{k}
\end{gathered}
$$




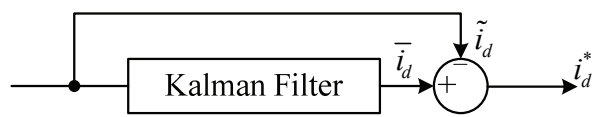

(a)

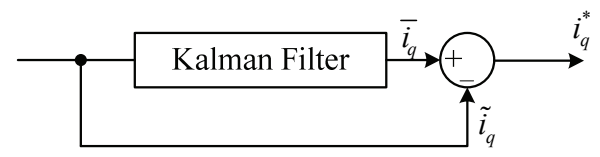

(b)

Fig. 3. Kalman Filter harmonics estimation: (a) d-axis component; (b) q-axis component

where;

$x_{k} \quad=$ state of system

$z_{k} \quad=$ measurement state

$u_{k-1}=$ control input of system

$A=$ matrix of previous state to current state

$B=$ matrix of control input to current state

$H \quad$ = matrix of measurement state to system

$w_{k-1}=$ system error

$v_{k} \quad=$ measurement error

In order to separate the harmonics from the fundamental of the load currents, it is enough to separate the direct term of the state system and measurement state from the original equation. Fig. 3 shows the principle of this extraction filter.

Based on Eq. (1), the estimation states of dynamic system can be obtain from the noisy measurement. Since there is no plant to control, therefore the input signal $\left(u_{k-1}\right)$ and system error $\left(w_{k-1}\right)$ can be neglected. Therefore, it can be written as;

$$
\begin{gathered}
i_{d(k)}=A i_{d(k-1)} \\
\tilde{l}_{d(k)}=H i_{d(k)}+v_{k}
\end{gathered}
$$

By exploiting the Eq. (2), the time update (predicator) and measurement update (corrector) are show in Eq. (3) and (4).

Time update equation;

$$
\begin{gathered}
\hat{\imath}_{d(k)}^{-}=A \hat{\imath}_{d(k-1)} \\
P_{k}^{-}=A P_{k-1} A^{T}+Q
\end{gathered}
$$

Measurement update equation;

$$
\begin{aligned}
& \hat{\imath}_{d(k)}=\hat{\imath}_{d(k)}^{-}+K_{k}\left(i_{d(k)}-H \hat{\imath}_{d(k)}^{-}\right) \\
& K_{k}=\frac{P_{k}^{-} H^{T}}{H P_{k}^{-} H^{T}+R} \\
& P_{k}=\left(I-K_{k} H\right) P_{k}^{-}
\end{aligned}
$$

where;

$i_{d(k)}=$ measurement of DC current

$\hat{\imath}_{d(k)}=$ estimation DC reference current

$\hat{\imath}_{d(k)}^{-}=$predicted state of DC reference current

$P_{k} \quad=$ estimation error covariance

$P_{k}^{-} \quad=$ predicted error covariance

$$
\begin{array}{ll}
K_{K} & =\text { Kalman Gain } \\
I & =\text { Identity matrix }
\end{array}
$$

The time update equation and measurement update equation were calculated continuously for each time step. The measurement error, " $R$ " could be specified offline, prior to the operation of the filter (refer Table 2). While measurement of system error covariance, " $Q$ ", is difficult to determine due to inability to directly observe the estimating process. Therefore to determine the optimum value of $Q$, a study have been conducted by looking at the THD using different values of $Q$ which represented in Fig. 4. From the graph, the optimum value of $Q$ to reduce the THD is 1e-8. Other parameters are shown in Table 2, while the cycle of the time update and the measurement update equation was shown in Fig. 5.

Table 2. Parameter of KF estimator

\begin{tabular}{c|c}
\hline Variables & Initial Condition \\
\hline Estimated current state, $\hat{\imath}_{d(k-1)}$ & 0.5 (initial) \\
\hline Estimated error covariance, $P_{k-1}$ & 1 (initial) \\
\hline State transition matrix & $A=[1]$ \\
\hline Measurement matrix & $H=[1]$ \\
\hline Measurement noise covariance, $R$ & 4 \\
\hline
\end{tabular}

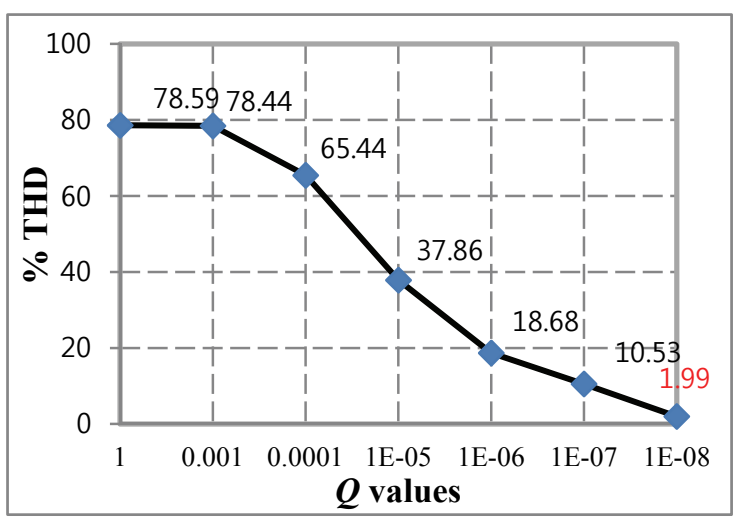

Fig. 4. Graph THD versus $Q$ values.

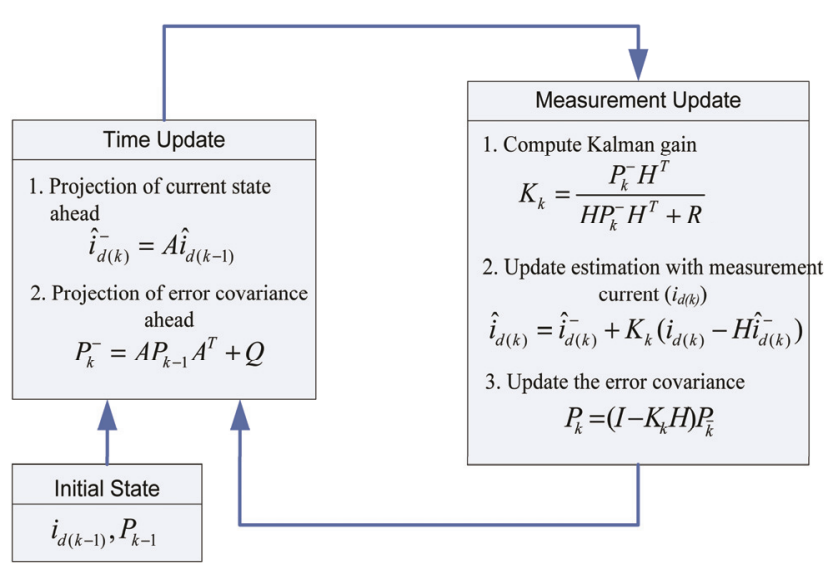

Fig. 5. Cycle of Discrete Kalman filter 


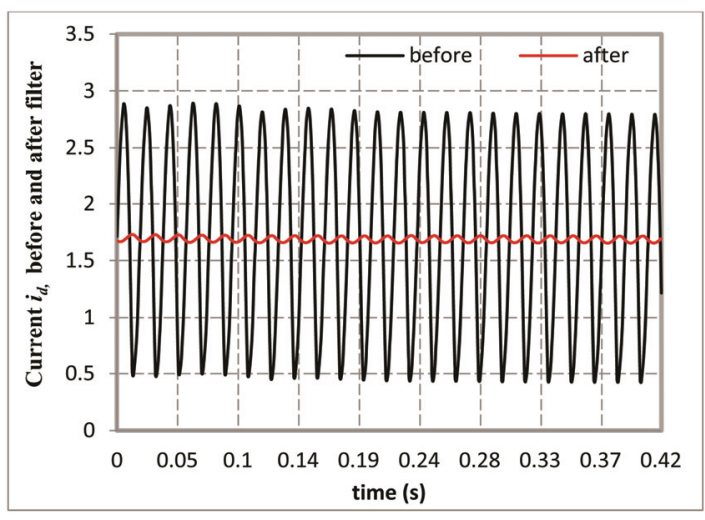

Fig. 6. Current at $d$-axis $\left(i_{d}\right)$

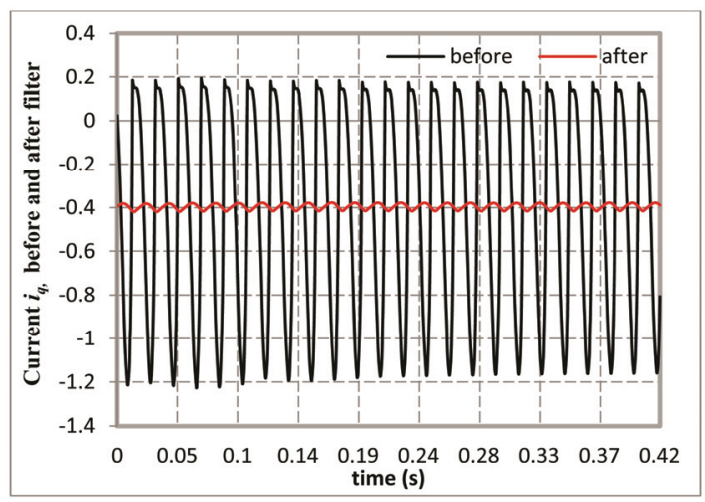

Fig. 7. Current at $q$-axis $\left(i_{q}\right)$

Initial state of " $i_{d(k-1)}$ " and " $P_{k-1}$ " were set at 1 before the operation. After the process started, the filter would continuously update the value according to the input state and measurement value. The same parameters of $\mathrm{KF}$ estimator were also used for $q$-axis. Fig. 6 and Fig. 7 shows the DC current waveform before and after KF estimator was implemented for $d$-axis and $q$-axis. From the, it is observed that after the KF was implemented, only the fundamental current is obtained (red line).

\subsection{Three-phase reference current generation em- ploying Kalman filter estimator}

This unit is design to generate the required current reference that is used to compensate the undesirable load currents components. In this case, the load currents are measured and transform into $d-q$ coordinates (rotating reference frame with fundamental frequency) using Park transformations. The equations to transform $a-b-c$ coordinate into $\alpha-\beta-0$ coordinate is presented in Eq. (5).

$$
\left[\begin{array}{l}
i_{o} \\
i_{\alpha} \\
i_{\beta}
\end{array}\right]=\sqrt{\frac{2}{3}}\left[\begin{array}{ccc}
1 / \sqrt{2} & 1 / \sqrt{2} & 1 / \sqrt{2} \\
1 & -1 / 2 & -1 / 2 \\
0 & \sqrt{3} / 2 & -\sqrt{3} / 2
\end{array}\right]\left[\begin{array}{l}
i_{L a} \\
i_{L b} \\
i_{L c}
\end{array}\right]
$$

By employing Park transformation, the $\alpha-\beta-0$ coordinate

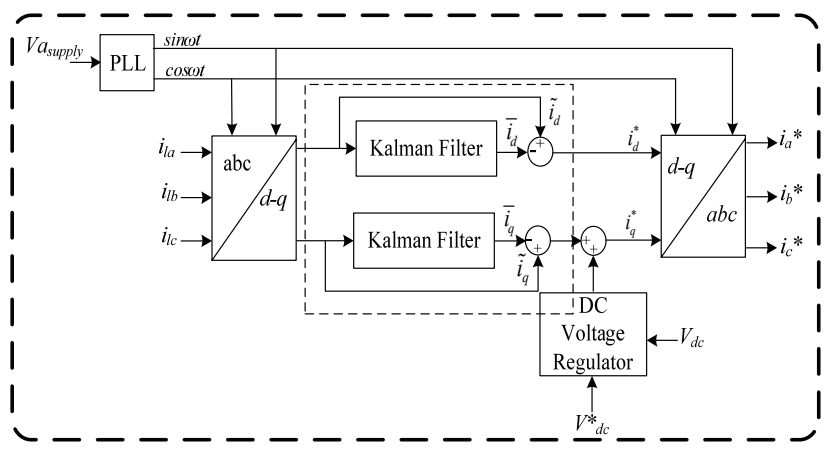

Fig. 8. New technique of three-phase reference current generator employing Kalman filter estimator

is transform into $d-q$ coordinate as shown in Eq. (5)

$$
\left[\begin{array}{l}
i_{d} \\
i_{q}
\end{array}\right]=\left[\begin{array}{cc}
\cos \theta & \sin \theta \\
-\sin \theta & \cos \theta
\end{array}\right]\left[\begin{array}{l}
i_{\alpha} \\
i_{\beta}
\end{array}\right]
$$

where; $\theta=\tan ^{-1}\left(\frac{i_{\beta}}{i_{\alpha}}\right)$

The phase angle, $\theta$ in $d-q$ frame is the same with fundamental frequency which makes the DC fundamental current component $\left(i_{\bar{d}}, i_{\bar{q}}\right)$ and harmonics AC component $\left(i_{\tilde{d}}, i_{\tilde{q}}\right)$ arise due to harmonics at the load [6]. Conventionally, low-pass filter are used to determine the DC component. However, phase shift in harmonics and high transient response are commonly obtained in the system before the system achieved its steady state. Therefore, KF estimator are used to overcome the problem from the low-pass filter hence help to improve the overall performance of the THD. In order to stabilize the voltage on the DC side of the VSI, the measurement voltage, $V_{d c}$ measure must follow the reference voltage, $V_{d c}$ ref. Therefore, PI-improved voltage regulator loop is designed by integrating a suitable PI controller. Fig. 8 shows the techniques to determine the harmonics component in the system.

\subsection{DC voltage regulator}

The DC voltage regulator is controlled with a traditional PI controller. In the block diagram show in Fig. 8, the DC voltage $V_{d c}$ is measured and then compared with a constant reference value $V_{d c}{ }^{*}$. The error is process by a PI controller with two gains; $K_{p}$ and $K_{i}$. Both gain are calculated and tuned accordingly to the dynamic response which the values of both gain are set to 4 for $K_{p}$ and 91 for $K_{i}$.

\section{Experimental Setup}

The new structure of the three-phase reference current generation employing KF estimator as shown in Fig. 1, whereas Fig. 9 shown the experimental test rig. The experiment uses 75A insulated bipolar transistor (IGBT) 


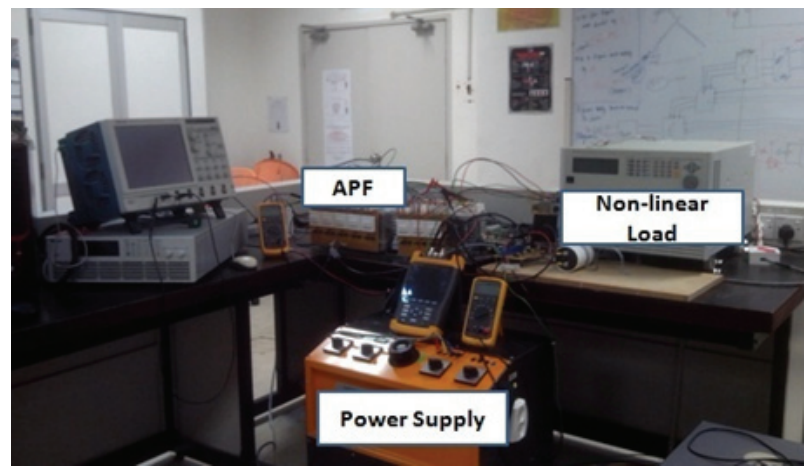

Fig. 9. Experimental test rig

(semikron SKM 75GB123D), IGBT driver dual module (SKHI22AR) DC link capacitor $(2200 \mu \mathrm{F}, 450 \mathrm{VDC})$, current sensor circuit (LEM HY-10P), voltage sensor (LV25-P), three-phase high switching inductor (3mH). The shunt APF is connected to a line voltage at $50 \mathrm{~Hz}$ and $120 \mathrm{~V}$ (rms line-line). The shunt APF control is implemented on a dSPACE 1104 DSP controller to generate the switching pattern. the non-linear load used in the studies are threephase load inductor, three phase power bridge rectifier module (SKD62/08), current sensor circuit (LEM HY-10P), DC capacitor $(1100 \mu \mathrm{F}, 400 \mathrm{~V})$ and three-phase resistor load). The voltage supply is set to $120 \mathrm{Vrms}$ and the sampling time is set at $100 \mu$ s for dSPACE. The tests are conducted to evaluate the performance of the APF when having variation of load.

\section{Simulation and Experimental Results}

The simulation and experimental results of the proposed three-phase reference current generation employing $\mathrm{KF}$ estimator for three-phase shunt APF are presented. The work is simulated and implemented using Matlab/simulink and dSPACE.

\subsection{Non-linear load}

The results for the APF before and after compensation are by simulated using Matlab/simulink while Fluke Power Quality Analyzer capture the results for the experimental. Fig. 10 (a) and (b) shows the supply current waveform before the compensation for simulation and experimental result thus, the harmonics spectrum of both simulation and experimental are shown in Fig. 11 respectively.

From the harmonic spectrum results, the total harmonics distortion (THD) can be determine by using the formula as define as;

$$
\% T H D=\frac{\sqrt{\sum_{n=2}^{\infty} I_{h}^{2}}}{I_{f}}
$$

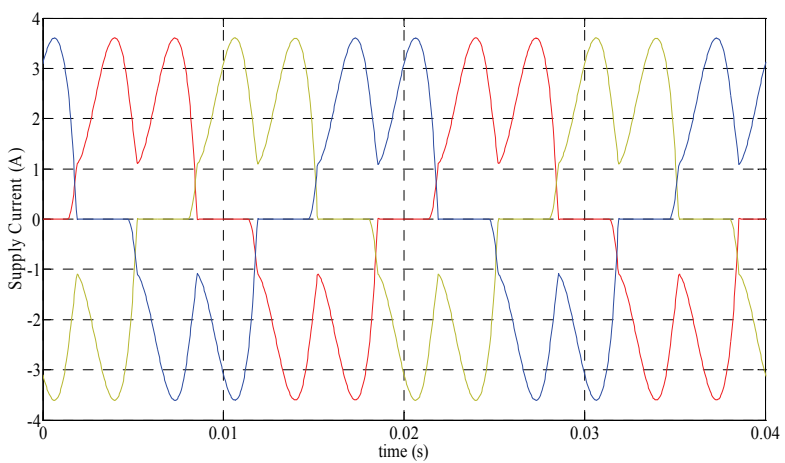

(a) Simulation

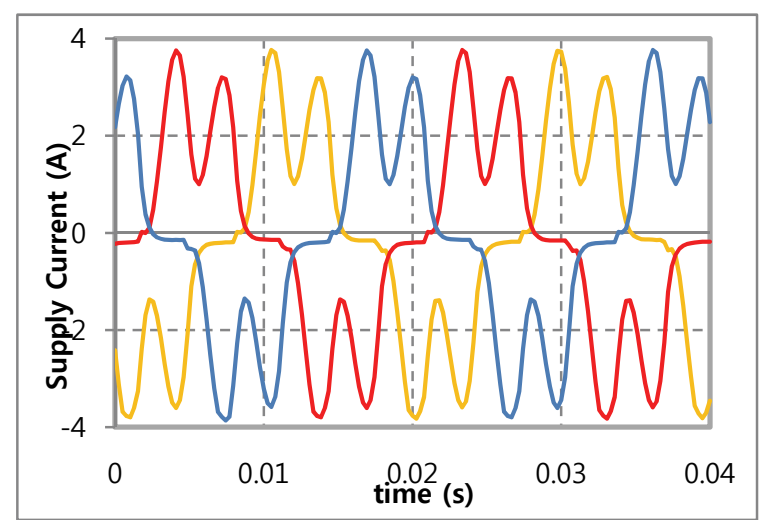

(b) Experimental

Fig. 10. Simulation and experimental result without shunt APF

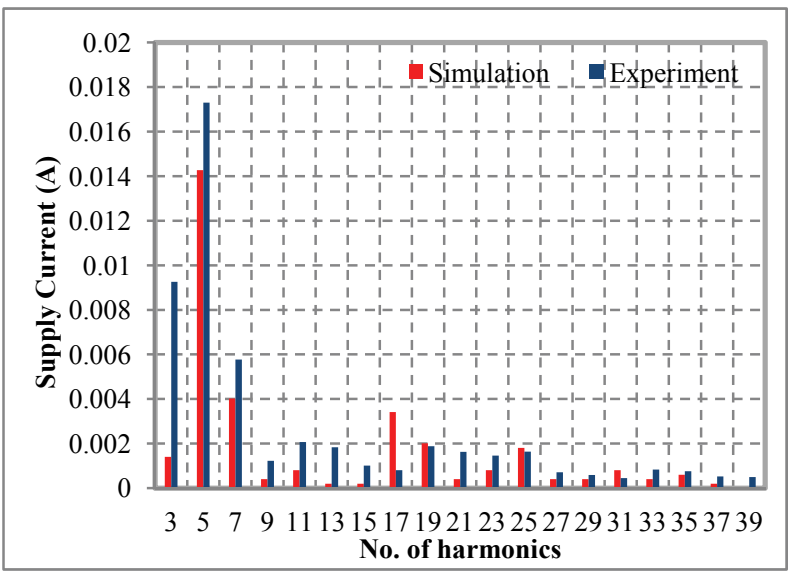

Fig. 11. Harmonic spectrum before the compensation

where;

$$
\begin{array}{ll}
I_{h} & : \text { harmonics component } \\
I_{f} & : \text { fundamental component } \\
n & : \text { harmonics number; } 2,3,4, \text { etc. }
\end{array}
$$

Therefore, the THD of the line current obtain by the simulation is $56.14 \%$ while the experimental obtain about $47.26 \%$. There are slightly different between the simulation and experimental results because the simulation is simulated 
at ideal condition.

\subsection{Kalman filter estimator result versus low-pass filter}

Commonly, when applying $d-q$ algorithm a Butterworth low-pass filter is used to filter out the unwanted DC component to ensure the correct reference currents are been generated in the system. Fail to obtain the correct reference current will reduce the overall performance of the active power filter (APF). However, when applying the low-pass filter, there are time delay which contribute to the phase shift in harmonics and high transient current. Fig. 12 shows the shunt APF when applying Butterworth low-pass filter. From the waveform, it clearly shows that the waveform

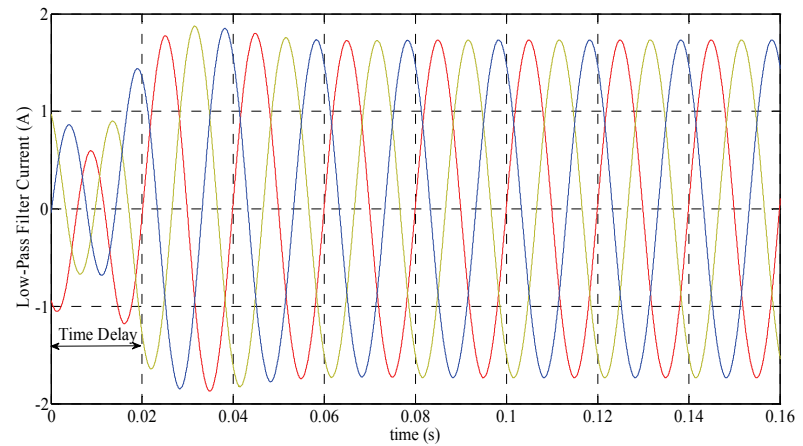

Fig. 12. Simulation Butterworth low-pass filter

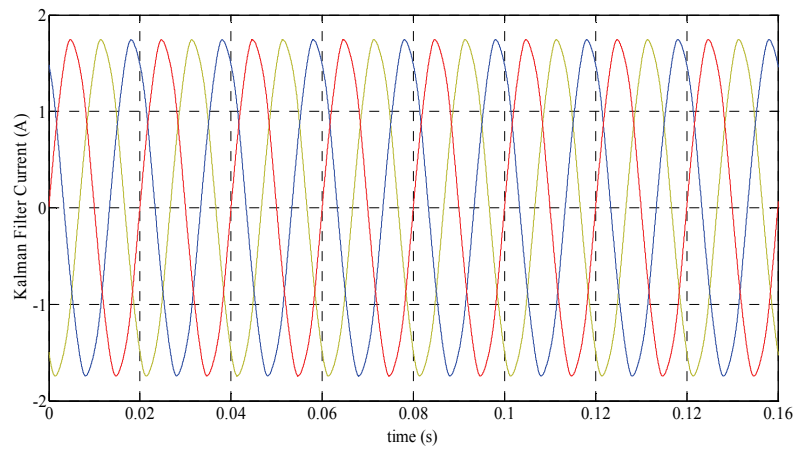

Fig. 13. Simulation Kalman filter

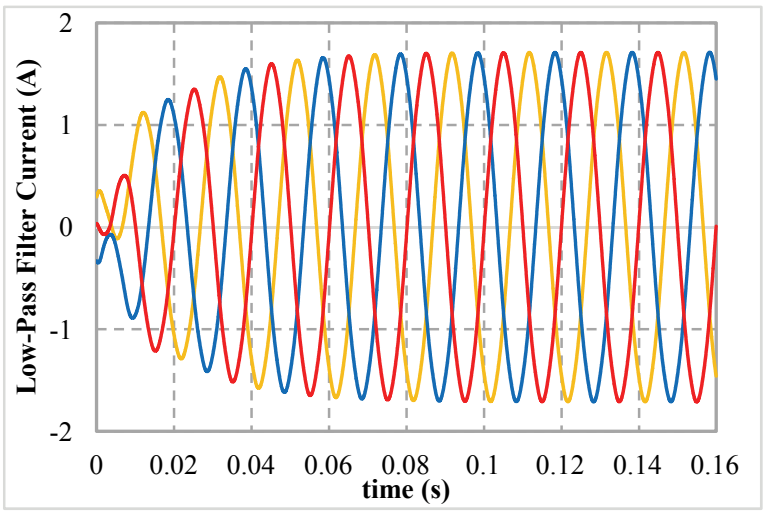

Fig. 14. Experimental Butterworth low-pass filter having almost $0.02 \mathrm{~s}$ delay with $43.36 \%$ of THD. On the other hands, there is no time delay when applying the shunt APF using KF estimator which is shown in Fig. 13. Therefore, the THD produce by the KF estimator is better compared to low-pass filter which about $0.77 \%$. On the other hand, the experimental results for low-pass and KF is shown in Fig. 14 and Fig. 15 respectively.

\subsection{Three-phase shunt active power filter}

In this shunt active power filter feeding a non-linear load, the results between Butterworth low-pass filter and KF estimator are compared between simulation and experimental

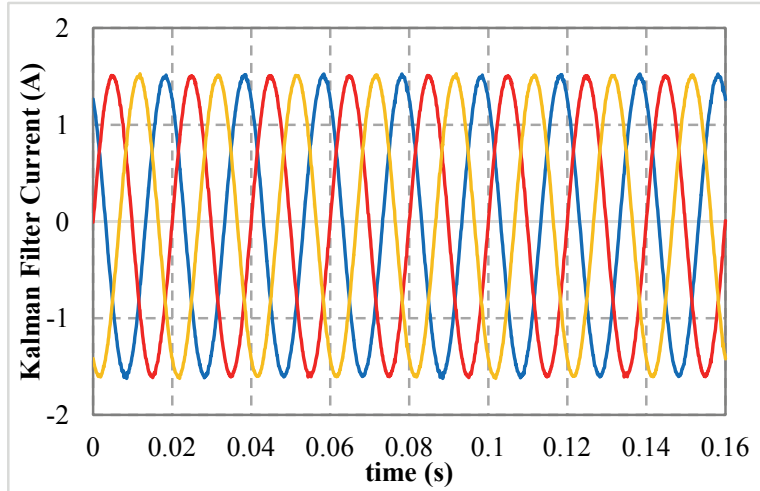

Fig. 15. Experimental Kalman filter

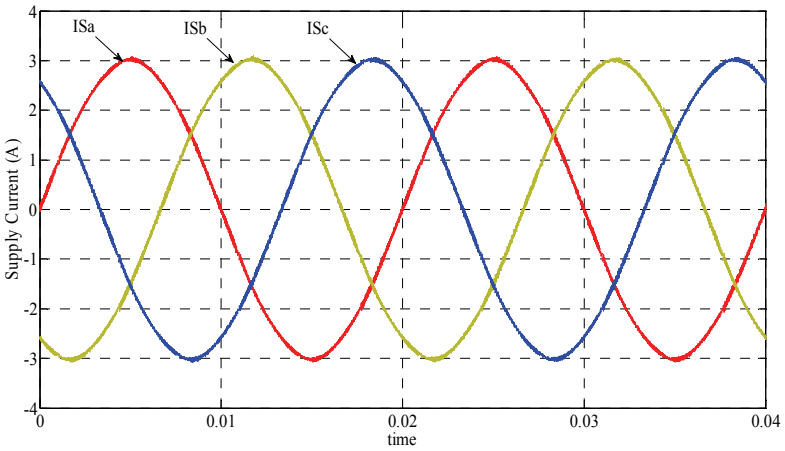

(a) Low-pass filter

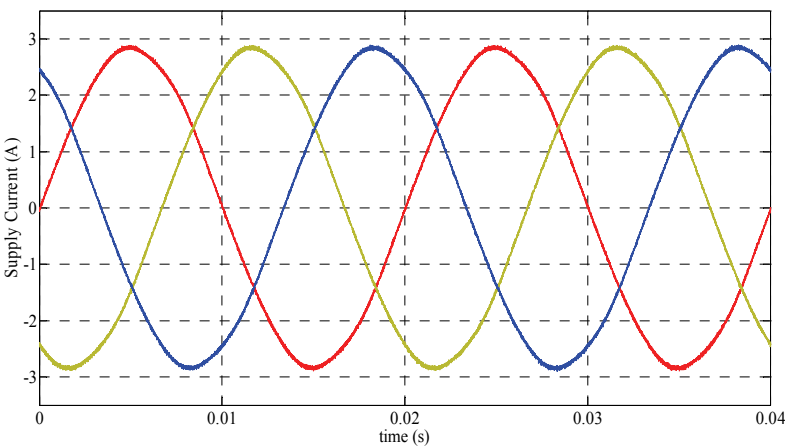

(b) Kalman filter

Fig. 16. Simulation result for shunt APF (a) low-pass filter, (b) Kalman filter 
are shown in Fig. 16 and Fig. 17 respectively.

From the results obtain, it can be concluded that almost the same waveform were produced for both simulation and experimental approach. Furthermore, the harmonics spectrum form the experimental are shown in Fig. 18.

It is clearly shown that all the harmonics component were reduce when applying both low-pass filter and KF. In addition, the fundamental current for both techniques were found almost identical between simulation and experimental. The THD results obtain shows that the new techniques shunt APF abide the regulation of IEEE 5191992 standard. Table 3 and Table 4 shows the THD after simulation and experimental results respectively.

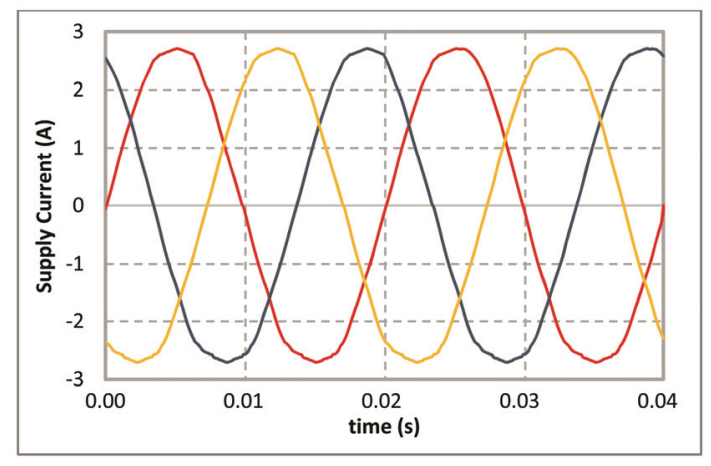

(a) Low-pass filter

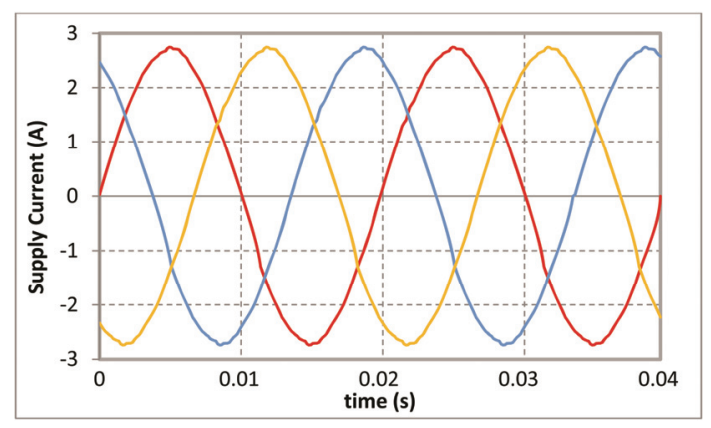

(b) Kalman Filter

Fig. 17. Experimental results for shunt APF: (a) low-pass filter; (b) Kalman filter

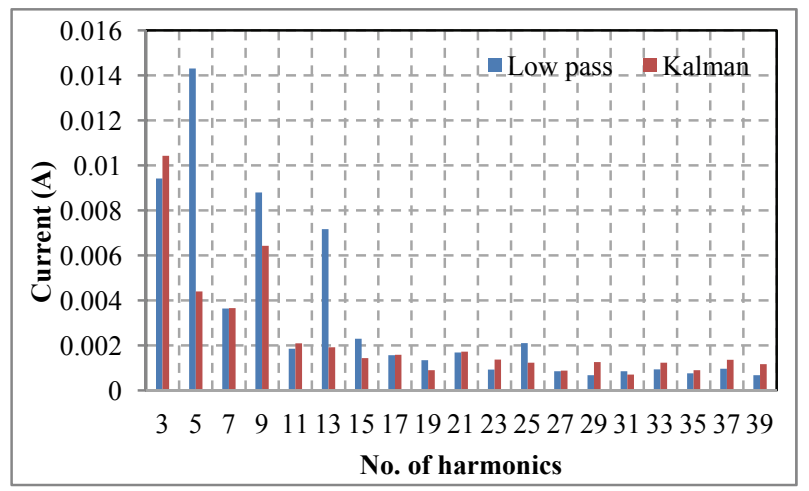

Fig. 18. Harmonics spectrum
Table 3. Simulation results

\begin{tabular}{c|c|c}
\hline Types of reference current generation & THD before & THD after \\
\hline Low-pass filter & \multirow{2}{*}{$55.88 \%$} & $2.09 \%$ \\
& & $1.99 \%$ \\
\hline Kalman filter estimator & &
\end{tabular}

Table 4. Experimental results

\begin{tabular}{c|c|c}
\hline Types of reference current generation & THD before & THD after \\
\hline Low-pass filter & \multirow{2}{*}{$47.27 \%$} & $2.30 \%$ \\
Kalman filter estimator & & $2.18 \%$ \\
\hline
\end{tabular}

From the observation, the shunt APF using KF estimator technique produce about $0.1 \%$ better THD compared to lowpass filter either in simulation and experimental. About THD of improvement from simulation and experimental are produce by using KF.

\section{Operation with Three-Phase Induction Motor Speed Drive}

A $1.5 \mathrm{~kW}, 380 \mathrm{~V}$ variable speed induction motor (IM) drive is connected in parallel to the APF and the threephase supply voltages. The motor is operated as a nonlinear load and starts to accelerate from standstill at time, $t$ $=0.06 \mathrm{~s}$ until it reached the required reference speed which is set at 1400 RPM. The supply current when the motor start to accelerate without shunt APF is shown in Fig. 19 while Fig. 20 shows the supply current waveform when applying shunt APF. The THD of the supply currents is measured at steady state condition $(t=0.28 \mathrm{~s})$ using Fluke Power Quality Analyser. The THD without shunt APF obtained from the supply current is $168.39 \%$, while the THD reduced to $2.38 \%$ and $2.80 \%$ when shunt APF employing KF and low-pass filter. Furthermore, in Fig. 21 until Fig. 23 shows the harmonic spectrum with or without shunt APF for both KF and low-pass filter. It can conclude that from the results, the shunt APF employing KF basedestimator produced lower THD compared to low-pass filter for an induction motor drive application.

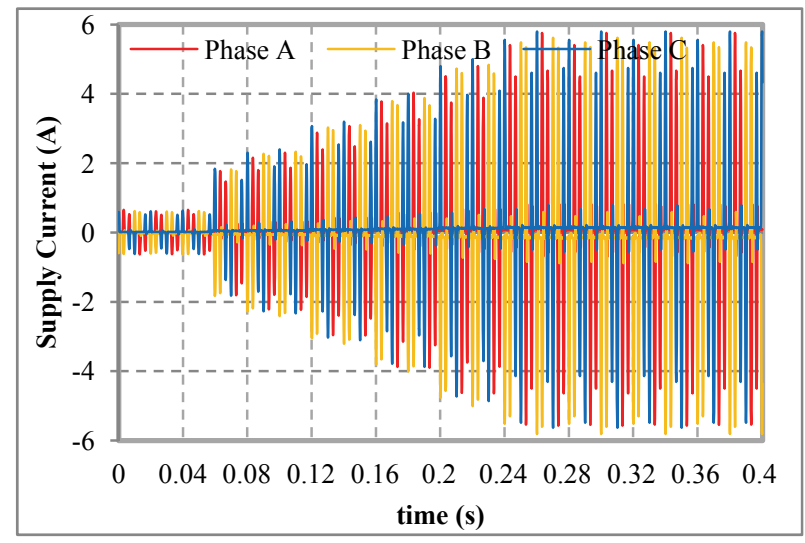

Fig. 19. Supply current waveform without shunt APF 


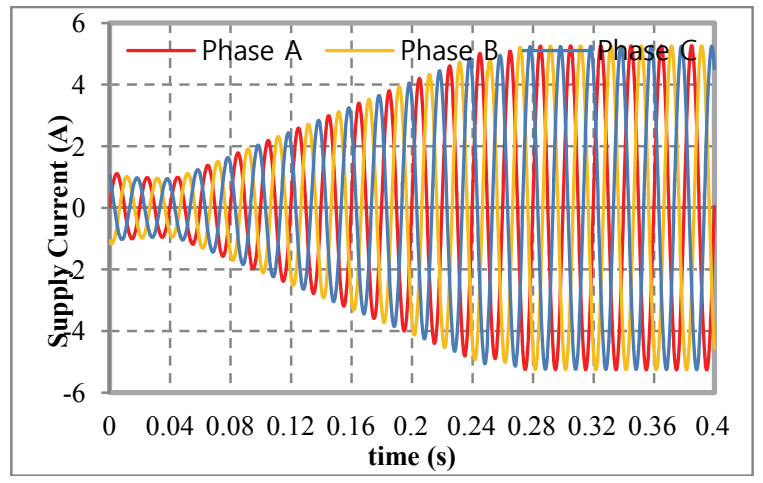

Fig. 20. Supply current when applying shunt APF with Kalman filter estimator

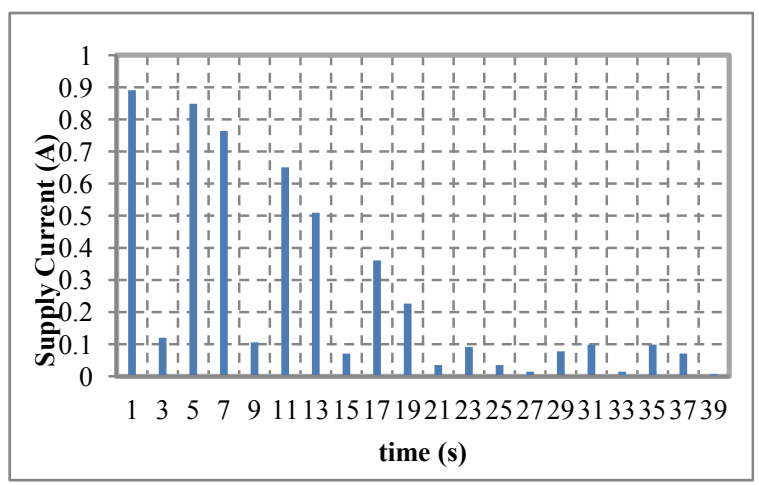

Fig. 21. Harmonic spectrum without shunt APF

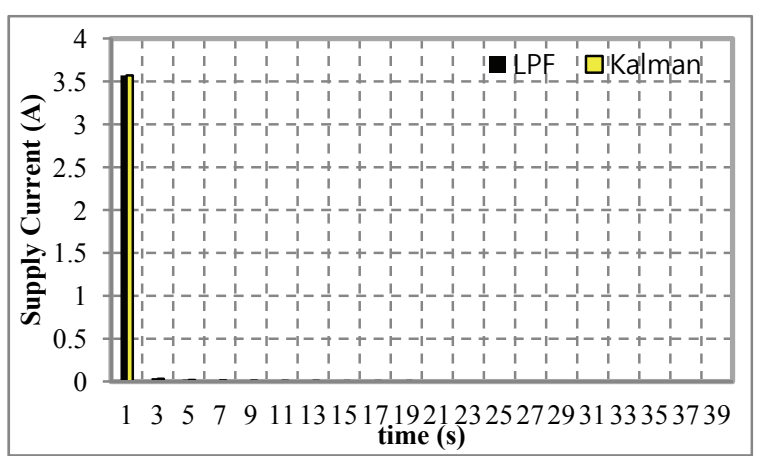

Fig. 22. Harmonics spectrum after applying shunt APF

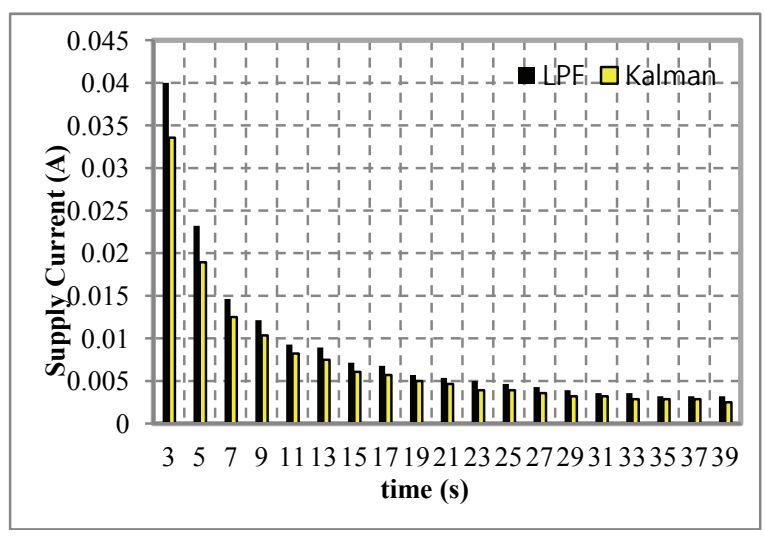

Fig. 23. Harmonics spectrum without fundamental
Table 5. THD of supply current before and after applying shunt APF

\begin{tabular}{c|c|c}
\hline Reference current generation & THD before & THD after \\
\hline Low-pass filter & \multirow{2}{*}{$168.39 \%$} & $2.80 \%$ \\
\cline { 1 - 1 } Kalman Filter estimator & & $2.38 \%$ \\
\hline
\end{tabular}

The overall total harmonic distortion with or without shunt APF is showed tabulated in Table 5 which shows that the KF estimator produce lower THD compared to lowpass filter for three-phase induction motor.

\section{Conclusion}

This paper proposed a new techniques of current reference generator by employing KF estimator for shunt APF technique. The simulation and hardware results have validated the proposed technique in generating the threephase reference current towards reducing the THD. For the three-phase rectifier connected with $\mathrm{RC}$ load, the performance of the proposed technique is comparable with those based on the low-pass filter reference current generation. The THD of the source current from the experimental result after the compensation is $2.18 \%$ which is less than $5 \%$ of the harmonics limit imposed by the IEEE 519 standard. In addition, almost $0.1 \%$ THD improvement was obtain by the proposed techniques compared to lowpass filter. Thus, the comparison of different reference current grid generation for shunt APF is also presented. The performance of KF estimator reference current generation was also studied for induction motor variable speed drive. In induction motor almost $0.42 \%$ improvement of THD was gather when applying KF estimator compared to low-pass filter.

\section{Acknowledgements}

The author's would like to acknowledge their gratitude to the Universiti Pertahanan Nasional Malaysia for providing the resources and supported through the grant UPNM/ 2015/GPJP/2/TK/06.

\section{References}

[1] H. Akagi, "Active Harmonic Filters," Proceedings of the IEEE, vol. 93, pp. 2128-2141, 2005.

[2] F. Z. Peng, H. Akagi, and A. Nabae, "A new approach to harmonic compensation in power systems-a combined system of shunt passive and series active filters," Industry Applications, IEEE Transactions on, vol. 26, pp. 983-990, 1990.

[3] H. Rudnick, J. Dixon, and L. Moran, "Delivering clean and pure power," Power and Energy Magazine, 
IEEE, vol. 1, pp. 32-40, 2003.

[4] P. Fang Zheng, "Application issues of active power filters," Industry Applications Magazine, IEEE, vol. 4, pp. 21-30, 1998.

[5] K. R. Uyyuru, M. K. Mishra, and A. Ghosh, "An Optimization-Based Algorithm for Shunt Active Filter Under Distorted Supply Voltages," Power Electronics, IEEE Transactions on, vol. 24, pp. 1223-1232, 2009.

[6] L. Asiminoaei, F. Blaabjerg, and S. Hansen, "Detection is key - Harmonic detection methods for active power filter applications," Industry Applications Magazine, IEEE, vol. 13, pp. 22-33, 2007.

[7] T. Quoc-Nam and L. Hong-Hee, "An Advanced Current Control Strategy for Three-Phase Shunt Active Power Filters," Industrial Electronics, IEEE Transactions on, vol. 60, pp. 5400-5410, 2013.

[8] R. S. Herrera, P. Salmeron, J. R. Vazquez, S. P. Litran, and A. Perez, "GENERALIZED instantaneous reactive power theory in poly-phase power systems," in Power Electronics and Applications, 2009. EPE '09. 13th European Conference on, 2009, pp. 1-10.

[9] K. Kelesidis, G. Adamidis, and G. Tsengenes, "Investigation of a control scheme based on modified $p-q$ theory for single phase single stage grid connected PV system," in Clean Electrical Power (ICCEP), 2011 International Conference on, 2011, pp. 535-540.

[10] M. A. Mulla, C. Rajagopalan, and A. Chowdhury, "Hardware implementation of series hybrid active power filter using a novel control strategy based on generalised instantaneous power theory," Power Electronics, IET, vol. 6, pp. 592-600, 2013.

[11] A. Esfandiari, M. Parniani, and H. Mokhtari, "A new control strategy of shunt active filters for power quality improvement of highly and randomly varying loads," in Industrial Electronics, 2004 IEEE International Symposium on, 2004, pp. 1297-1302, vol. 2.

[12] R. R. Sawant and M. C. Chandorkar, "Methods for multi-functional converter control in three-phase fourwire systems," Power Electronics, IET, vol. 2, pp. 5266, 2009.

[13] P. Salmeron, R. S. Herrera, and J. R. Vazquez, "Mapping matrices against vectorial frame in the instantaneous reactive power compensation," Electric Power Applications, IET, vol. 1, pp. 727-736, 2007.

[14] A. Bhattacharya, C. Chakraborty, and S. Bhattacharya, "Parallel-Connected Shunt Hybrid Active Power Filters Operating at Different Switching Frequencies for Improved Performance," Industrial Electronics, IEEE Transactions on, vol. 59, pp. 4007-4019, 2012.

[15] Y. Suresh, A. K. Panda, and M. Suresh, "Real-time implementation of adaptive fuzzy hysteresis-band current control technique for shunt active power filter," Power Electronics, IET, vol. 5, pp. 1188-1195, 2012.

[16] S. K. Jain and S. N. Singh, "Harmonics estimation in emerging power system: Key issues and challenges,"
Electric Power Systems Research, vol. 81, pp. 17541766, 2011.

[17] V. M. Moreno, A. P. Lopez, and R. I. D. Garcias, "Reference current estimation under distorted line voltage for control of shunt active power filters," Power Electronics, IEEE Transactions on, vol. 19, pp. 988-994, 2004.

[18] J. F. Petit, G. Robles, and H. Amaris, "Predictive algorithm for harmonic mitigation in non-linear loads based on active filters," in Power Tech, 2005 IEEE Russia, 2005, pp. 1-6.

[19] J. A. Rosendo, A. Bachiller, and A. Gomez, "Application of Self-Tuned Kalman Filters to Control of Active Power Filters," in Power Tech, 2007 IEEE Lausanne, 2007, pp. 1262-1265.

[20] R. Cardoso, R. F. de Camargo, H. Pinheiro, and H. A. Grundling, "Kalman filter based synchronisation methods," Generation, Transmission \& Distribution, IET, vol. 2, pp. 542-555, 2008.

[21] R. Panigrahi, P. C. Panda, and B. D. Subudhi, "Comparison of performances of hysteresis and dead beat controllers in active power filtering," in Sustainable Energy Technologies (ICSET), 2012 IEEE Third International Conference on, 2012, pp. 287-292.

[22] P. Regulski and V. Terzija, "Estimation of Frequency and Fundamental Power Components Using an Unscented Kalman Filter," Instrumentation and Measurement, IEEE Transactions on, vol. 61, pp. 952-962, 2012.

[23] J. M. Kanieski, R. Cardoso, H. Pinheiro, and H. A. Grundling, "Kalman Filter-Based Control System for Power Quality Conditioning Devices," Industrial Electronics, IEEE Transactions on, vol. 60, pp. 52145227, 2013.

[24] H. M. Beides and G. T. Heydt, "Dynamic state estimation of power system harmonics using Kalman filter methodology," Power Delivery, IEEE Transactions on, vol. 6, pp. 1663-1670, 1991.

[25] H. Ma and A. A. Girgis, "Identification and tracking of harmonic sources in a power system using a Kalman filter," Power Delivery, IEEE Transactions on, vol. 11, pp. 1659-1665, 1996.

[26] V. Moreno, A. Pigazo, and R. I. Diego, "Reference estimation technique for active power filters using a digital Kalman algorithm," in Harmonics and Quality of Power, 2002. 10th International Conference on, 2002, pp. 490-494 vol. 2.

[27] P. Salmeron and S. P. Litran, "Improvement of the Electric Power Quality Using Series Active and Shunt Passive Filters," Power Delivery, IEEE Transactions on, vol. 25, pp. 1058-1067, 2010.

[28] L. Limongi, R. Bojoi, G. Griva, and A. Tenconi, "Digital current-control schemes," Industrial Electronics Magazine, IEEE, vol. 3, pp. 20-31, 2009.

[29] F. P. Zeng, G. H. Tan, J. Z. Wang, and Y. C. Ji, "Novel 
single-phase five-level voltage-source inverter for the shunt active power filter," Power Electronics, IET, vol. 3, pp. 480-489, 2010.

[30] O. Vodyakho, T. Kim, S. Kwak, and C. S. Edrington, "Comparison of the space vector current controls for shunt active power filters," Power Electronics, IET, vol. 2, pp. 653-664, 2009.

[31] O. Vodyakho and T. Kim, "Shunt active filter based on three-level inverter for three-phase four-wire systems," Power Electronics, IET, vol. 2, pp. 216-226, 2009.

[32] K. Nishida, M. Rukonuzzaman, and M. Nakaoka, "Digital control three-phase shunt active power filter with a new harmonic-current-extraction process," Generation, Transmission and Distribution, IEE Proceedings-, vol. 152, pp. 529-538, 2005.

[33] C. Changqing, W. Liping, and Y. Guohui, "A threephase active power filter based on park transformation," in Computer Science \& Education, 2009. ICCSE '09. 4th International Conference on, 2009, pp. 1221-1224.

[34] A. Pigazo, V. M. Moreno, and E. J. Estebanez, "A Recursive Park Transformation to Improve the Performance of Synchronous Reference Frame Controllers in Shunt Active Power Filters," Power Electronics, IEEE Transactions on, vol. 24, pp. 2065-2075, 2009.

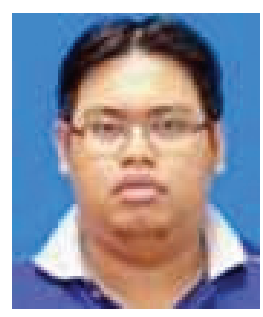

Ahmad Shukri Abu Hasim received his Diploma, Bachelor's degree, and Master degree in Electrical Engineering major in power from Universiti Teknologi Mara, Malaysia, in 2000, 2004, and 2008, respectively. He is a lecturer at Universiti Pertahanan Nasional Malaysia and currently pursuing his Ph.D. at Universiti Teknikal Malaysia Melaka. His research areas are power electronic and drive systems.

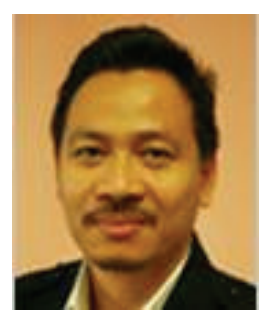

Zulkifilie Ibrahim was born in Malaysia in 1966. He received his B.S. degree in engineering from University of Technology, Malaysia, in 1989 and his Ph.D. degree from Liverpool John Moores University, UK, in 1999. He has been an associate professor at Universiti Teknikal Malaysia Melaka, Malaysia, since 2006. His main research interests are power electronics, fuzzy logic control, embedded system design, and electric motor drives.

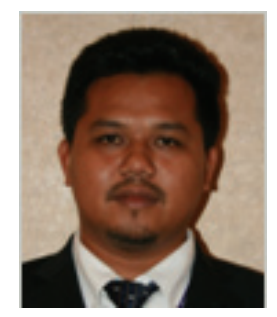

Md. Hairul Nizam Talib was born in Malaysia, in 1976. He received his B.S. in Electrical Eng from Universiti Teknologi Malaysia (UTM) in 1999, Malaysia, M.S. in Electrical Eng. from University of Nottingham, UK in 2005 and his Ph.D. from Universiti Teknikal Malaysia Melaka (UTeM), Malaysia in 2016. He was a lecturer at UTeM since 2002. His research interests include power electronics, fuzzy logic control and motor drives.

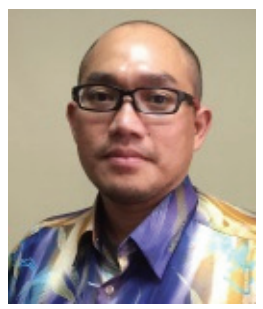

Syed Mohd. Fairuz Bin Syed Mohd. Dardin received his $\mathrm{Ph} . \mathrm{D}$ in signal processing under Signal, Image, Coustic $\&$ Optimisation domain from Institut Supérieur de l'Aéronautique et de l'Espace (ISAE-Supaero), Toulouse in 2015. He is currently a lecturer in the Department of Electrical \& Electronics Engineering, National Defense University of Malaysia. His research interest includes GNSS receiver algorithm and architecture and GNSS/INS integration focusing on improvement in harsh environment. 